\title{
THE RELATIONSHIP BETWEEN HEART RATE RESERVE AND OXYGEN UPTAKE RESERVE IN HEART FAILURE PATIENTS ON OPTIMIZED AND NON-OPTIMIZED BETA-BLOCKER THERAPY
}

\author{
Vitor Oliveira Carvalho, Guilherme Veiga Guimarães, Edimar Alcides Bocchi
}

doi: $10.1590 / \mathbf{S 1 8 0 7 - 5 9 3 2 2 0 0 8 0 0 0 6 0 0 0 0 3}$

Carvalho VO, Guimarães GV, Bocchi EA. The relationship between heart rate reserve and oxygen uptake reserve in heart failure patients on optimized and non-optimized beta-blocker therapy. Clinics. 2008;63:725-30.

BACKGROUND: The relationship between the percentage of oxygen consumption reserve and percentage of heart rate reserve in heart failure patients either on non-optimized or off beta-blocker therapy is known to be unreliable. The aim of this study was to evaluate the relationship between the percentage of oxygen consumption reserve and percentage of heart rate reserve in heart failure patients receiving optimized and non-optimized beta-blocker treatment during a treadmill cardiopulmonary exercise test.

METHODS: A total of 27 sedentary heart failure patients ( $86 \%$ male, $50 \pm 12$ years) on optimized beta-blocker therapy with a left ventricle ejection fraction of $33 \pm 8 \%$ and 35 sedentary non-optimized heart failure patients (75\% male, $47 \pm 10$ years) with a left ventricle ejection fraction of $30 \pm 10 \%$ underwent the treadmill cardiopulmonary exercise test (Naughton protocol). Resting and peak effort values of both the percentage of oxygen consumption reserve and percentage of heart rate reserve were, by definition, 0 and 100 , respectively.

RESULTS: The heart rate slope for the non-optimized group was derived from the points $0.949 \pm 0.088$ ( 0 intercept $)$ and $1.055 \pm 0.128$ ( 1 intercept), $\mathrm{p}<0.0001$. The heart rate slope for the optimized group was derived from the points $1.026 \pm 0.108$ ( 0 intercept) and $1.012 \pm 0.108$ ( 1 intercept), $\mathrm{p}=0.47$. Regression linear plots for the heart rate slope for each patient in the non-optimized and optimized groups revealed a slope of 0.986 (almost perfect) for the optimized group, but the regression analysis for the non-optimized group was 0.030 (far from perfect, which occurs at 1 ).

CONCLUSION: The relationship between the percentage of oxygen consumption reserve and percentage of heart rate reserve in patients on optimized beta-blocker therapy was reliable, but this relationship was unreliable in non-optimized heart failure patients.

KEYWORDS: Heart rate; Beta-blockers; Oxygen consumption; Heart failure; Exercise.

\section{INTRODUCTION}

Heart failure is considered to be the last stage of heart disease, and it is a significant cause of mortality and morbidity in the world. ${ }^{1}$ In recent years, beta-blocker therapy has become a primary pharmacologic intervention in patients with heart failure. Although improvement in aerobic capacity has not been proven, ${ }^{2}$ the use of this therapy arises from an

Laboratório de Insuficiência Cardíaca e Transplante - Instituto do Coração, Hospital das Clínicas, Faculdade de Medicina, Universidade de São Paulo (InCor HC-FMUSP) - São Paulo/SP, Brazil.

Email: vitor.carvalho@usp.br

Tel.: 55113069.5419

Received for publication on July 2, 2008

Accepted for publication on July 30, 2008 abundance of evidence demonstrating that beta-blockers improve survival and reduce hospitalization. ${ }^{3}$

The cardiopulmonary exercise test is a well-established technique used in heart failure patients to evaluate peak oxygen consumption $\left(\mathrm{pVO}_{2}\right)$. Oxygen consumption $\left(\mathrm{VO}_{2}\right)$ is the best prognostic variable in heart failure patients, and it remains so even in the beta-blocker era. ${ }^{4}$ Aerobic exercise training is also a well-established non-pharmacological method used to increase $\mathrm{pVO}_{2}$ in heart failure patients. In this population, prescription of adequate aerobic exercise intensity based on heart rate is crucial to permit both an increase in exercise capacity and reasonable control of exercise-related risk. ${ }^{1,5,6}$

Heart rate and $\mathrm{VO}_{2}$ are strongly related from rest to the peak of the treadmill cardiopulmonary exercise test in normal 
individuals. ${ }^{7}$ This association is especially true when the relationship between the percentage heart rate reserve (\%HRR) and percentage oxygen consumption reserve $\left(\% \mathrm{VO}_{2} \mathrm{R}\right)$ is considered. ${ }^{8}$ A previous study demonstrated that the $\% \mathrm{VO}_{2} \mathrm{R}$ versus $\% \mathrm{HRR}$ relationship was unreliable for aerobic effort relative intensity assessment in heart failure patients that were on or off beta-blocker therapy. However, these patients were not optimized with a beta-blocker therapy. ${ }^{8}$

The aim of this study was to evaluate the \%HRR$\% \mathrm{VO}_{2} \mathrm{R}$ relationship in heart failure patients on optimized and non-optimized beta-blocker therapy during a treadmill cardiopulmonary exercise test.

\section{MATERIALS AND METHODS}

\section{Study population}

Twenty-seven sedentary heart failure patients ( $86 \%$ male, $50 \pm 12$ years) on optimized beta-blocker therapy with a left ventricle ejection fraction of $33 \pm 8 \%$ (echocardiography) and thirty-five sedentary non-optimized heart failure patients (75\% male, $47 \pm 10$ years) with a left ventricle ejection fraction of $30 \pm 10 \%$ were included in the study. Data were collected from March 2006 to February 2008. Characteristics of the heart failure patients are listed in Table 1. Patients with the following conditions were excluded from the study: atrial fibrillation, use of a pacemaker, noncardiovascular functional limitations (e.g. osteoarthritis), chronic obstructive pulmonary disease, and patients not receiving beta-blocker therapy. Optimization was defined as $50 \mathrm{mg} / \mathrm{day}$ or more of Carvedilol and a resting heart rate between 50 and 60 beats per minute for at least three months. ${ }^{9}$

This protocol was approved by the Ethical Committee of the study institution. All patients provided informed consent before participation.

\section{Cardiopulmonary exercise test}

Heart failure patients receiving optimized or non-optimized beta-blocker therapy were asked to refrain from any strenuous physical activities for 24 hours before testing and to avoid the consumption of any stimulants (e.g., coffee, tobacco, alcohol) that especially may influence heart rate. Their last meal was ingested at least three hours before the start of the test. All subjects underwent the cardiopulmonary exercise test on a programmable treadmill (Series 2000; Marquette Electronics;

Table 1 - Characteristics of the heart failure patients

\begin{tabular}{|c|c|c|c|}
\hline Characteristics & Non-Optimized & Optimized & $\mathrm{p}$ \\
\hline \multicolumn{4}{|l|}{ Etiology: } \\
\hline Ischemic & $40 \%$ & $37 \%$ & NS \\
\hline Idiopathic dilated cardiomyopathy & $57 \%$ & $48 \%$ & NS \\
\hline Hypertensive & $3 \%$ & $15 \%$ & $<0.0001$ \\
\hline \multicolumn{4}{|l|}{ NYHA functional class: } \\
\hline I & $20 \%$ & $42 \%$ & NS \\
\hline II & $37 \%$ & $20 \%$ & NS \\
\hline III & $43 \%$ & $38 \%$ & NS \\
\hline \multicolumn{4}{|l|}{ Current medications: } \\
\hline Diuretics & $94 \%$ & $93 \%$ & NS \\
\hline Furosemide & $74 \%, 42 \pm 15 \mathrm{mg} /$ day & $63 \%, 50 \pm 30 \mathrm{mg} /$ day & NS \\
\hline hydrochlorothiazide & $20 \%, 25 \pm 0 \mathrm{mg} /$ day & $30 \%, 28 \pm 9 \mathrm{mg} / \mathrm{day}$ & NS \\
\hline ACE inhibitor & $82 \%$ & $80 \%$ & NS \\
\hline enalapril & $68 \%, 25 \pm 16 \mathrm{mg} /$ day & $65 \%, 38 \pm 6 \mathrm{mg} / \mathrm{day}$ & NS \\
\hline Captopril & $14 \%, 25 \pm 15 \mathrm{mg} /$ day & $15 \%, 94 \pm 37 \mathrm{mg} /$ day & 0.006 \\
\hline Angiotensin II AT1 receptor antagonists (losartan) & $18 \% 83 \pm 29 \mathrm{mg} /$ day & $20 \%, 80 \pm 27 \mathrm{mg} /$ day & NS \\
\hline$\beta$-Adrenergic receptor blocker (Carvedilol) & $100 \%, 21 \pm 7 \mathrm{mg} /$ day & $100 \%, 53 \pm 10 \mathrm{mg} /$ day & $<0.0001$ \\
\hline Spironolactone & $70 \%, 26 \pm 4 \mathrm{mg} /$ day & $35 \%, 25 \pm 0 \mathrm{mg} / \mathrm{day}$ & NS \\
\hline Digoxin & $64 \%, 0.25 \pm 0 \mathrm{mg} /$ day & $46 \%, 0.25 \pm 0 \mathrm{mg} / \mathrm{day}$ & NS \\
\hline Isosorbide 5-mononitrate & $14 \%, 45 \pm 16 \mathrm{mg} /$ day & $19 \%, 56 \pm 35 \mathrm{mg} /$ day & NS \\
\hline Hydralazine & $8 \%, 37 \pm 18 \mathrm{mg} /$ day & $19 \%, 80 \pm 27 \mathrm{mg} /$ day & NS \\
\hline
\end{tabular}


Milwaukee, WI, USA) in a temperature-controlled room $\left(21-23^{\circ} \mathrm{C}\right)$ between 10:00 a.m. and 3:00 p.m. Patients were monitored via standard 12 lead continuous electrocardiograms (Max 1; Marquette Electronics; Milwaukee, WI, USA) and auscultation for blood pressure. Minute ventilation, oxygen uptake, carbon dioxide output, and other cardiopulmonary variables were acquired breath-by-breath by a computerized system (Vmax 229 model, SensorMedics, Yorba Linda, CA, USA). The resting $\mathrm{VO}_{2}$ and heart rate were computed as the mean values for the final 30 seconds of the resting period, whereas the $\mathrm{pVO}_{2}$ and peak heart rate were the mean values for the final 30 seconds of effort before exhaustion. The heart rate reserve and oxygen consumption reserve were calculated as the difference between the peak and resting heart rate and the mean $\mathrm{VO}_{2}$ value, respectively. The $\% \mathrm{HRR}$ was calculated as: $\% \mathrm{HRR}=$ submaximal heart rate - rest heart rate $/$ heart rate reserve $\mathrm{x} 100$. The $\% \mathrm{VO}_{2} \mathrm{R}$ was calculated as: $\% \mathrm{VO}_{2} \mathrm{R}$ $=$ submaximalVO $2-$ restVO $2 / \mathrm{VO}_{2}$ reserve $\mathrm{x} 100 .{ }^{10}$ Resting and peak effort values of both the $\% \mathrm{VO}_{2} \mathrm{R}$ and $\% \mathrm{HRR}$ were, by definition, 0 and 100, respectively. Respiratory exchange ratios were recorded as the average of samples obtained during each stage for each heart failure patient's protocol (modified Naughton protocol). A satisfactory cardiopulmonary exercise test was characterized by a respiratory exchange ratio of greater than 1.05 and symptoms of maximum effort.

\section{Current medication intake}

All heart failure patients received a beta-blocker (Carvedilol) and an angiotensin converting enzyme inhibitor (Enalapril/Captopril) or an angiotensin II AT1 receptor antagonist (losartan). The medication profile of the heart failure patient group is shown in Table 1. Patients took a beta-blocker, Angiotensin Converting Enzyme inhibitors, Angiotensin II AT1 receptor antagonists, and Isosorbide 5-mononitrate two times per day. Half of the daily dose was taken in the morning (9:00 a.m.), and the other half was taken at night (9:00 p.m.). Diuretics, digoxin, and spironolactone were taken in the morning (9:00 a.m.).

\section{STATISTICAL ANALYSIS}

Descriptive analyses are presented as mean and standard deviation (SD). Linear regression and Pearson product moment coefficients were used to determine the relationship between the $\% \mathrm{HRR}$ and $\% \mathrm{VO}_{2} \mathrm{R}$ in both heart failure groups. The \%HRR was chosen as the independent variable since it is currently used in rehabilitation programs to predict $\% \mathrm{VO}_{2} \mathrm{R}$ values (i.e., aerobic exercise relative intensity) in the absence of a basal cardiopulmonary exercise test. A one-sample $t$-test was used to verify whether the means of individual slopes and y-intercepts differed from those of the corresponding group regression and from the line of identity (i.e., from slope $=1$ and $y$-intercept $=0$ ). This methodology was used in a previous study. ${ }^{10}$

To compare the rest, peak, and reserve heart rates, age, Body Mass Index $\left(\mathrm{Kg} / \mathrm{m}^{2}\right)$, respiratory exchange ratio, left ventricle ejection fraction, $\mathrm{pVO}_{2}, \mathrm{VO}_{2}$ reserve, and current medication between optimized and non-optimized beta-blocker therapy groups, we used one-sample $t$-tests. To compare heart failure etiology and New York Heart Association functional class, we used Fisher's exact test.

Data were analyzed using Statistical Package for Social Sciences (SPSS) for Windows, v 11.5 (SPSS Inc, Chicago, IL). Statistical significance was defined as $\mathrm{p}<0.05$.

\section{RESULTS}

\section{Demographic and clinical characteristics}

The non-optimized and optimized groups were well matched for age, body mass index and sex (Table 2). The only noted difference in etiology was hypertension and in current medication intake were Captopril and Carvedilol. There were no observed significant differences in the New York Heart Association functional class (Table 1).

\section{Ergometric characteristics}

As expected, the rest and peak heart rates in the optimized beta-blocker therapy group were lower than those in the non-optimized group. Heart rate reserve did not differ between the groups (Table 2).

The $\mathrm{pVO}_{2}$ and $\mathrm{VO}_{2}$ reserve in the optimized group did not differ from those in the non-optimized group. The respiratory exchange ratio also did not differ between the groups (Table 2).

\section{Regression analysis}

The $\% \mathrm{VO}_{2} \mathrm{R}$ was strongly related to the $\% \mathrm{HRR}$ in optimized and non-optimized patients analyzed stage-bystage during the cardiopulmonary exercise test $(r=0.95$, $\mathrm{p}<0.0001$ with 9.3 of residual SD and $\mathrm{r}=0.91, \mathrm{p}<0.0001$ with 12.7 of residual $\mathrm{SD}$, respectively). The mean regression line coincided with the line of identity in the optimized betablocker therapy group $(\mathrm{p}=0.31)$, but this relationship was not observed in non-optimized patients $(\mathrm{p}=0.012)$ (Figures 1 and 2).

The mean heart rate slope for the non-optimized group was derived from the points $0.949 \pm 0.088$ ( 0 intercept) and $1.055 \pm 0.128$ ( 1 intercept) and had a $95 \%$ of confidence 
Table 2 - Characteristics of the heart failure patients

\begin{tabular}{lccc}
\hline Characteristics & Non-Optimized & Optimized & $\mathrm{p}$ \\
\hline Age, years & $47 \pm 10$ & $50 \pm 12$ & $\mathrm{NS}$ \\
Male, $\%$ & 86 & 75 & $\mathrm{NS}$ \\
Body Mass Index, $\mathrm{Kg} / \mathrm{m}^{2}$ & $26 \pm 4$ & $25 \pm 3$ & $\mathrm{NS}$ \\
Respiratory Exchange Ratio & $1.08 \pm 0.05$ & $1.10 \pm 0.08$ & $\mathrm{NS}$ \\
$\mathrm{LVEF}($ echocardiography), $\%$ & $30 \pm 10$ & $33 \pm 8$ & $\mathrm{NS}$ \\
$\mathrm{pVO}_{2}, \mathrm{mLO}_{2} \cdot \mathrm{Kg}^{-1} \cdot \mathrm{min}^{-1}$ & $18 \pm 5$ & $19.6 \pm 6$ & $\mathrm{NS}$ \\
$\mathrm{VO}_{2}$ Reserve, $\mathrm{mLO}_{2} \mathrm{Kg}^{-1} \cdot \mathrm{min}^{-1}$ & $14,9 \pm 4,5$ & $16,6 \pm 5,7$ & $\mathrm{NS}$ \\
$\mathrm{Resting} \mathrm{Heart} \mathrm{Rate,} \mathrm{bpm}_{\text {Peak Heart Rate, } \mathrm{bpm}}$ & $79 \pm 10$ & $58 \pm 3$ & $<0.0001$ \\
Heart Rate reserve, $\mathrm{bpm}$ & $125 \pm 16$ & $111 \pm 19$ & 0.008 \\
\hline
\end{tabular}

LVEF: Left ventricle ejection fraction; $p V O 2$ : Peak Oxygen Consumption.

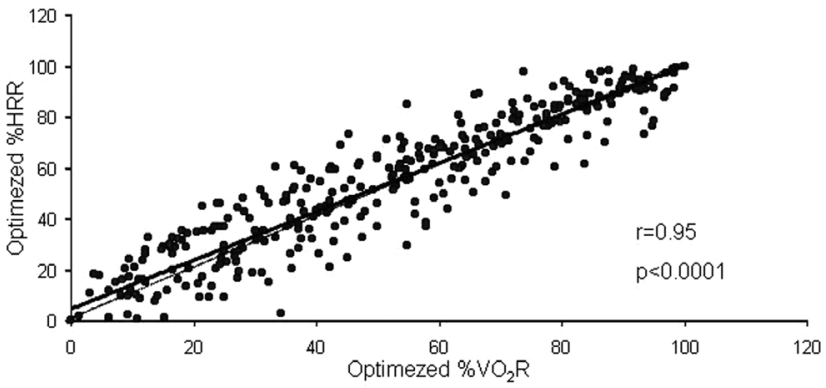

Figure 1 - Relationship between percentage of heart rate reserve (\%HRR) and percentage of oxygen consumption reserve $\left(\% \mathrm{VO}_{2} \mathrm{R}\right)$ in optimized heart failure patients. The plot represents stage by stage regression of the cardiopulmonary exercise test. The dotted is the identity line, the full line is regression line

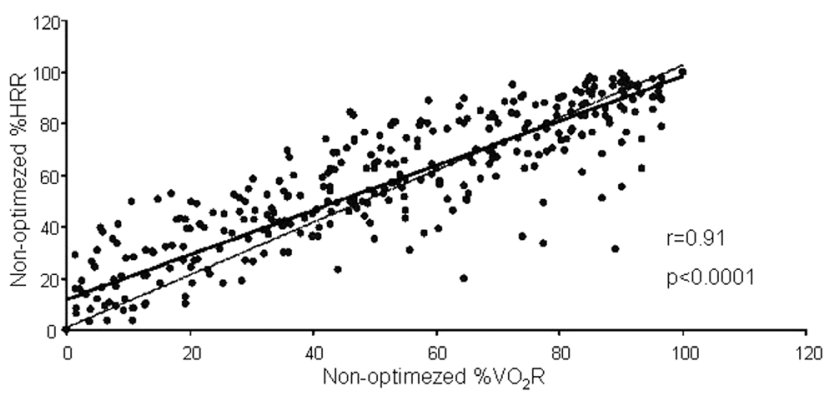

Figure 2 - Relationship between percentage of heart rate reserve (\%HRR) and percentage of oxygen consumption reserve $\left(\% \mathrm{VO}_{2} \mathrm{R}\right)$ in non-optimized heart failure patients. The plot represents stage by stage regression of the cardiopulmonary exercise test. The dotted line is the identity line, the full line

interval from -0.171 to $-0.537(\mathrm{p}<0.0001)$. The heart rate slope for the optimized group was derived from the points $1.026 \pm 0.108$ (0 intercept) and 1.012 \pm 0.108 and had a confidence interval from -0.011 to $0.016(\mathrm{p}=0.47)$.

Regression linear plots for the heart rate slope during the cardiopulmonary exercise test for each patient in the nonoptimized and optimized groups are shown in Figure 3. This
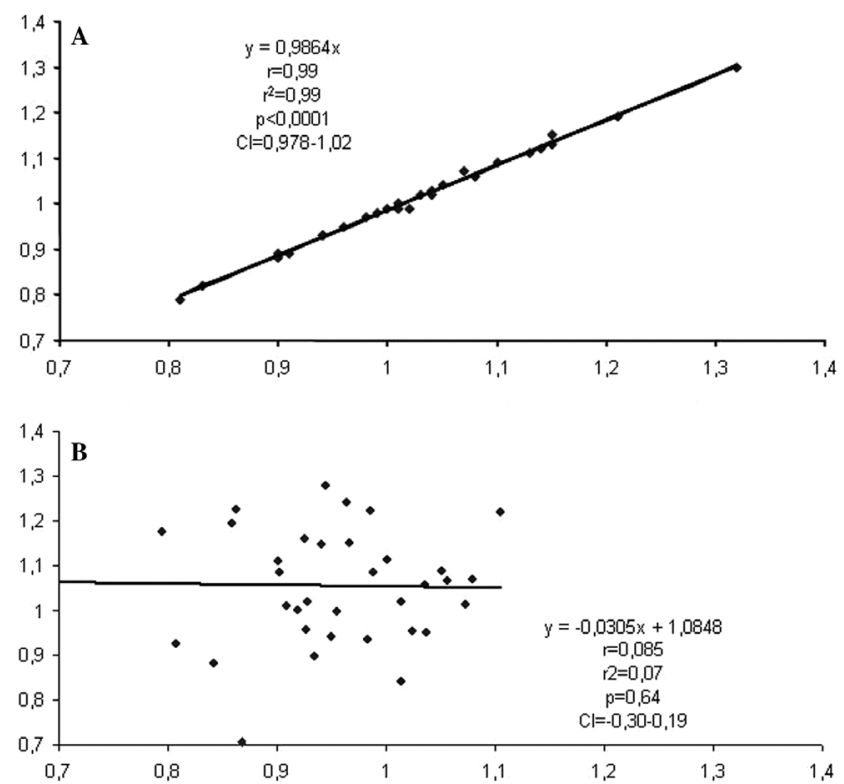

Figure 3 - Linear regression between 0 intercept and 1 intercept HR slope of each optimized(A) and non-optimized(B) heart failure patient

regression analysis revealed a slope of 0.986 (almost perfect, which is achieved with a slope of 1) for the optimized group, but the regression analysis for the non-optimized group was 0.030 (far from perfect, which occurs at values of less than 1).

\section{DISCUSSION}

The main finding of this study is that the use of the relationship between the $\% \mathrm{HRR}$ and $\% \mathrm{VO}_{2} \mathrm{R}$ for the aerobic effort relative intensity assessment and prescription is reliable for heart failure patients on optimized beta-blocker therapy but unreliable for non-optimized heart failure patients. 


\section{Relationship between the \% $\mathrm{HRR}$ and $\% \mathrm{VO}_{2} \mathrm{R}$ in non- optimized beta-blocker heart failure patients}

The $\% \mathrm{HRR}$ and $\% \mathrm{VO}_{2} \mathrm{R}$ are strongly related from rest to the peak of the treadmill cardiopulmonary exercise test in normal individuals. ${ }^{78}$ Motivated by the report of this relationship, Mezzani et al investigated the \%HRR and $\% \mathrm{VO}_{2} \mathrm{R}$ relationship in normal individuals and heart failure patients with and without beta-blocker therapy. ${ }^{8}$ The hypothesis that these heart failure patients would have the same comportment as normal individuals was frustrated by the non-coincidence between the regression line and identity line (i.e., the unreliability of the $\% \mathrm{HRR}-\% \mathrm{VO}_{2} \mathrm{R}$ relationship). In this case, the patients on beta-blocker therapy were administered a mean Carvedilol dose $(22 \pm 14$ $\mathrm{mg} /$ day) similar to that administered to those in our nonoptimized beta-blocker therapy group $(21 \pm 7 \mathrm{mg} /$ day $)$. As expected, the regression line in our study was similar to those reported in other studies for non-optimized heart failure patients. Based on the results from Mezzani et $\mathrm{al}^{8}$ and our study, we cannot assess the aerobic effort relative intensity and prescribe exercise using the \%HRR in nonoptimized beta-blocker therapy heart failure patients.

Another previous study evaluated the $\% \mathrm{HRR}-\% \mathrm{VO}_{2} \mathrm{R}$ relationship in heart failure patients with and without betablocker therapy and found a perfect identity between these variables. However, this study had a number of limitations. For example, a fixed rest $\mathrm{VO}_{2}$ value $\left(3.5 \mathrm{mLO}_{2} \mathrm{Kg}^{-1} \cdot \mathrm{min}^{-1}\right)$ was used, and no Carvedilol dosage was reported by the authors. ${ }^{11}$

\section{Relationship between the \% HRR and $\% \mathrm{VO}_{2} \mathrm{R}$ in heart failure patients on optimized beta-blocker therapy}

In our study, we found that the $\% \mathrm{HRR}-\% \mathrm{VO}_{2} \mathrm{R}$ relationship was at the line of identity in optimized heart failure patients. This finding provides evidence for the reliability of the $\% \mathrm{HRR}-\% \mathrm{VO}_{2} \mathrm{R}$ relationship, and it shows that the \%HRR can be used to prescribe exercise training and assess aerobic effort relative intensity.

Heart failure syndrome is characterized by an exacerbation of the sympathetic system, heart rate increase, and left ventricular dysfunction. ${ }^{12}$ This situation promotes poor cardiac function and decreased cardiac output. ${ }^{13,14}$ The maximal $\mathrm{VO}_{2}$ depends on cardiac output, which is expressed by the formula: $\mathrm{VO}_{2}=$ (systolic volume $\mathrm{X}$ heart rate) $\mathrm{X}$ arteriovenous oxygen difference. ${ }^{15}$ We hypothesized that optimized heart failure patients administered Carvedilol exhibit decreased heart rates and improved cardiac function during exercise, probably, more than the non-optimized patients. When we evaluated optimized patients, however, heart rate and sympathetic control seemed to be more rigorous (i.e., attenuated) and cardiac function improved during exercise. This may have restored the \%HRR$\% \mathrm{VO}_{2} \mathrm{R}$ relationship.

\section{Study limitations}

Our study is limited by the low number of assessed patients. Additionally, we studied only one type of betablocker (Carvedilol) using one method of cardiopulmonary exercise test (treadmill).

\section{CONCLUSION}

The $\% \mathrm{HRR}-\% \mathrm{VO}_{2} \mathrm{R}$ relationship in patients on optimized beta-blocker therapy was reliable during a treadmill cardiopulmonary exercise test, but this relationship was unreliable in non-optimized heart failure patients. Further studies are needed to fully understand $\% \mathrm{HRR}-\% \mathrm{VO}_{2} \mathrm{R}$ relationship in heart failure patients.

\section{ACKNOWLEDGEMENT}

This study was supported by the Coordenação de Aperfeiçoamento de Pessoal de Nível Superior.

\section{REFERENCES}

1. Working Group on Cardiac Rehabilitation \& Exercise Physiology and Working Group on Heart Failure of the European Society of Cardiology. Recommendations for exercise testing in chronic heart failure patients. Eur Heart J. 2001;22:37-45.

2. Witte KK, Thackray S, Nikitin NP, Cleland JG, Clark AL. The effects of long-term beta-blockade on the ventilatory responses to exercise in chronic heart failure. Eur J Heart Fail. 2005:7:612-7.

3. Lechat P, Packer M, Chalon S, Cucherat M, Arab T, Boissel JP. Clinical effects of beta-adrenergic blockade in chronic heart failure: a meta-analysis of double-blind, placebo-controlled, randomized trials. Circulation 1998:98:1184-91.
4. O'Neill JO, Young JB, Pothier CE, Lauer MS. Peak oxygen consumption as a predictor of death in patients with heart failure receiving betablockers. Circulation. 2005;111:2313-18.

5. Guimarães GV, Carvalho VO, Bocchi EA. Reproducibility of the selfcontrolled six-minute walking test in heart failure patients. Clinics. 2008;63:201-06.

6. Carvalho VO, Guimarães GV, Ciolac EG, Bocchi EA. Heart rate dynamics during a treadmill cardiopulmonary exercise test in optimized beta-blocked heart failure patients. Clinics. 2008 ;63:479-82. 
7. Swain DP, Leutholtz BC, King ME, Haas LA, Branch JD. Relationship between \% heart rate reserve and \% VO2reserve in treadmill exercise. Med Sci Sports Exerc. 1998;30:318-21.

8. Mezzani A, Corra U, Giordano A, Cafagna M, Adriano EP, Giannuzzi P. Unreliability of the \% VO2 reserve versus \%heart rate reserve relationship for aerobic effort relative intensity assessment in chronic heart failure patients on or off beta-blocking therapy. Eur J Cardiovasc Prev Rehabil. 2007;14:92-8.

9. Packer M, Coats A, Fowler M, Katus H, Krum H, Mohacsi P et al. Effect of Carvedilol on Survival in Severe Chronic Heart Failure. N Engl J Med. 2001; 344:1651-58.

10. Hui S, Chan J. The relationship between heart rate reserve and oxygen uptake reserve in children and adolescents. Res Q Exerc Sport. 2006;77:41-9.

11. Brawner CA, Keteyian SJ, Ehrman JK. The relationship of heart rate reserve to VO2 reserve in patients with heart disease. Med Sci Sports Exerc. 2002;34:418-22
12. Bocchi EA, Vilas-Boas F, Perrone S, Caamaño AG, Clausell N, Moreira Mda C. I Latin American Guidelines for the Assessment and Management of Decompensated Heart Failure. Arq Bras Cardiol. 2005;85:49-94.

13. Barone FC, Willette RN, Nelson AH, Ohlstein EH, Brooks DP, Coatney RW. Carvedilol prevents and reverses hypertrophy-induced cardiac dysfunction. Pharmacology. 2007;80:166-76.

14. Bocchi EA, Carvalho VO, Guimaraes GV. Inverse correlation between testosterone and ventricle ejection fraction, hemodynamics and exercise capacity in heart failure patients with erectile dysfunction. Int Braz J Urol. 2008;34:302-10.

15. Arena R, Myers J, Williams MA, Gulati M, Kligfield P, Balady GJ, et al. Assessment of functional capacity in clinical and research settings: a scientific statement from the American Heart Association Committee on Exercise, Rehabilitation, and Prevention of the Council on Clinical Cardiology and the Council on Cardiovascular Nursing Circulation. 2007; 116:329-43 